\title{
Role of Dexmedetomidine on Hemodynamics and Anesthetic Requirement During Elective Intracranial Tumor Surgery - A Prospective Randomized Double Blind Placebo Controlled Study
}

\author{
Authors \\ *Amrita Roy ${ }^{1}$, Suman Sarkar ${ }^{2}$, Sankari Santra $^{3}$, Anusua Banerjee ${ }^{4}$, Shanta Ganguly ${ }^{5}$ \\ ${ }^{1,3,5}$ Dept. of Anesthesiology, I.P.G.M.E\&R and SSKM Hospital. 244 A.J.C Bose Road, Kolkata, \\ PIN - 700020, India \\ Email Id: royamrita002@gmail.com,sankarisantra@yahoo.com,gangulyshanta@rediffmail.com \\ ${ }^{2}$ Dept. of Pediatrics, I.P.G.M.E\&R and SSKM Hospital.244 A.J.C Bose Road, Kolkata, PIN - 700020, India \\ Email:dr.sumansarkar@gmail.com \\ ${ }^{4}$ Dept. of Cardiac Anesthesiology, I.P.G.M.E\&R and SSKM Hospital 244 A.J.C Bose Road, Kolkata, PIN - \\ 700020, India
}

Department of Anesthesiology, I.P.G.M.E\&R, 244 A.J.C Bose Road, Kolkata, PIN - 700020, India Corresponding Author

Dr. Amrita Roy

M.D, RMO cum Clinical Tutor, Dept. of Anesthesiology, I.P.G.M.E\&R and SSKM Hospital Email Id: royamrita002@gmail.com, Phone no. +919432310162

\section{Abstract}

Background: The objective of present study was to compare the effects of dexmedetomidine with placebo on intraoperative hemodynamics and anesthetic requirements during intracranial tumor surgery.

Methods: Ninety patients of ASA physical status 1 or 2, scheduled for elective intracranial tumor surgery, were allocated into group D and group C each consisting of 45 patients. Group D received dexmedetomidine $1 \mu \mathrm{g} / \mathrm{kg}$ over 10 minutes followed by maintenance infusion $0.4 \mu \mathrm{g} / \mathrm{kg} / \mathrm{hr}$ which was discontinued at skin closure. Group C received normal saline in a similar manner. Anesthesia was induced after 20 minutes of starting the maintenance infusion with propofol and maintained with nitrous oxide in oxygen, continuous infusion of propofol, atracurium and intermittent fentanyl. Heart rate, systolic, diastolic and mean blood pressures were recorded and compared. The requirements of propofol and fentanyl in both groups were also compared.

Results: Dexmedetomidine significantly attenuated hemodynamic response at intubation, head pin fixation, skin incision, making of burr hole, opening of dura and at extubation (p 0.00). Total dose of propofol as well as induction and maintenance dose requirement were significantly lower in group $D(p<0.0001)$. Total and hourly fentanyl requirement was also less in group $D(<0.0001)$. Patients in group $D$ were extubated earlier than patients in group $C(p<0.0001)$. Group D patients required less postoperative analgesic ( $p 0.026)$.

Conclusion: Dexmedetomidine attenuated the hemodynamic response significantly, maintained perioperative hemodynamic stability, decreased extubation time as well as reduced intraoperative propofol and fentanyl and postoperative analgesic requirement in intracranial tumor surgery.

Key words: Dexmedetomidine, Propofol, Fentanyl, hemodynamics, Intracranial tumor surgery 


\section{Introduction}

The goals of neuroanesthesia are to maintain a stable cerebral hemodynamics and a good operating condition without sudden increase in brain volume and intracranial pressure. Rapid recovery from anesthesia is also required for early neurological evaluation. As the autoregulation is impaired in tumor region, sudden increase in arterial blood pressure is associated with intracranial bleeds and edema formation ${ }^{[1]}$. It may increase the morbidity and prolong hospital stay. Thus prevention and control of hemodynamic responses to varying degree of nociceptive stimuli at critical moments of anesthesia and surgery (e.g., laryngoscopy and endotracheal intubation, head pin fixation, skin incision, traction on pain sensitive structures, extubation) are of utmost importance to preserve cerebral homeostasis in neurosurgical patients. Routinely different anesthetic agents and antihypertensive medicines are used to maintain the stable hemodynamics. But they may take time to control hypertension followed by a subsequent period of hypotension or there may be delayed recovery from anesthesia.

Dexmedetomidine, an $\alpha-2$ adrenoreceptor agonist has recently been introduced in neuroanesthesia practice, because of its sympatholytic, sedative and hemodynamic stabilizing properties ${ }^{[2,3]}$. It is 16 times more potent than clonidine and having analgesic effects without significant respiratory depression ${ }^{[4]}$. Dexmedetomidine also reduces the need for opioid and anesthetic requirement and a potentially useful anesthetic adjuvant for neurosurgical cases ${ }^{[5]}$.

This study was designed to assess the efficacy of dexmedetomidine in controlling hypertensive response in patients undergoing intracranial tumor surgery under general anesthesia. Intraoperative anesthetic requirements were also noted as secondary outcome.

\section{Materials and Methods}

After obtaining approval from Institutional Ethics Committee, 90 patients aged 18-65 years, of either sex, of ASA status 1 or 2, with Glasgow Coma Scale of 14 or 15 and scheduled to undergo elective craniotomy for supratentorial tumor were enrolled in this study. The exclusion criteria were as follows: pregnant or nursing woman, morbid obesity, preoperative heart rate $<45$ beats $/ \mathrm{min}$, second or third degree heart block, medication with beta blocker, $\alpha$ methyl dopa, clonidine, or other $\alpha 2$ agonists, psychiatric diseases, renal and hepatic diseases.

Balanced randomization using permuted blocks was applied. The patients were randomized into two groups consisting of 45 patients in each group. Routine medications were continued as clinically applicable. Two hours before transferring the patient to the operating room, all puncture sites were treated with topical anesthetic cream. On arrival to operating room, a central venous line in subclavian vein and a radial arterial cannulation were done under local anesthesia for central venous and arterial pressure monitoring as well as for blood sampling. Drug was prepared and administered by one anesthesiologist who was completely unaware of the study objectives and data was collected by investigator. Group D, the Dexmedetomidine group received Dexmedetomidine $1 \mu \mathrm{g} / \mathrm{kg}$ over 10 minutes followed by a maintenance infusion of $0.4 \mu \mathrm{g} / \mathrm{kg} / \mathrm{hr}$. Induction of anesthesia was done after $20 \mathrm{~min}$ of starting the maintenance infusion. It was discontinued at skin closure. Dexmedetomidine was supplied in 2-mL ampoules of $100 \mu \mathrm{g} / \mathrm{ml}$ concentration, and this volume was diluted with $198 \mathrm{~mL}$ of normal saline to yield a final concentration of $1 \mu \mathrm{g} / \mathrm{ml}$. Group C, the placebo group received similar volumes of saline in similar manner. In both groups the bolus started $30 \mathrm{~min}$ before induction. All patients were preoxygenated, and then induced with intravenous Propofol $(1-2 \mathrm{mg} / \mathrm{kg})$ and Fentanyl $(2 \mu \mathrm{g} / \mathrm{kg})$. Tracheal intubation was facilitated with Atracurium $0.5 \mathrm{mg} / \mathrm{kg}$ as a bolus dose over $30 \mathrm{sec}$. Patients were moderately hyperventilated with Oxygen / Nitrous oxide (1:1) and was adjusted to maintain PaCO2 between 30 and $35 \mathrm{mmHg}$.

The anesthesia was maintained with Propofol and Atracurium infusion. Atracurium was administered by intravenous infusion at a rate of 0.5 $\mathrm{mg} / \mathrm{kg} / \mathrm{hr}$ and. Bolus doses of Fentanyl $(1 \mu \mathrm{g} / \mathrm{kg})$ 
were administered before head pin fixation. Propofol infusion was titrated to maintain a Bispectral index (BIS) of 40-60. Mannitol (1 $\mathrm{gm} / \mathrm{kg}$ ) was administered to every patient during the first burr hole. Dexmedetomidine or placebo infusions were stopped at starting of skin closure. Fluids for resuscitation and maintenance were provided with glucose free iso-osmolar crystalloid solutions 2-3 ml/kg/hr, and replacement of blood loss was done as per standard guideline. Urine output was monitored. All patients received Ondansetron $4 \mathrm{mg}$ and underwent routine reversal of neuromuscular blockade. Patients were awakened and extubated in the operating room and transferred to postanesthesia care unit after following simple commands.

Hemodynamic events that required treatment were defined as hypotension - Systolic blood pressure (SBP) < $90 \mathrm{~mm} \mathrm{Hg}$, hypertension - SBP> $180 \mathrm{~mm}$ $\mathrm{Hg}$ or diastolic blood pressure (DBP) $>105 \mathrm{~mm}$ $\mathrm{Hg}$ or mean arterial pressure (MAP) $>130 \mathrm{~mm}$ $\mathrm{Hg}$, bradycardia - heart rate $(\mathrm{HR})<50$ beats/minute, and tachycardia - HR >100 beats/min.

Hypertension and or tachycardia in spite of maintaining BIS 60 were managed with bolus i.v fentanyl $1-2 \mu \mathrm{g} / \mathrm{kg}$. If not corrected then incremental doses of labetolol $10 \mathrm{mg}$ was administered. Hypotension was managed with fluid and an incremental dose of phenylephrine 50 $\mu \mathrm{g}$. Bradycardia with hemodynamic instability was treated with $0.6 \mathrm{mg}$ i.v atropine.

The data of patients was collected by the investigator at the following time points - baseline (T0), after bolus dose (T1), at induction (T2), intubation (T3), head pin fixation (T4), skin incision (T5), making of burr hole (T6), opening of dura (T7) and extubation (T8).

The numbers of interventions done when hemodynamic variables were outside the predetermined window were recorded.

\section{Statistical analysis}

Data were expressed as mean \pm standard deviation (SD) for continuous normally distributed variables, median and interquartile range for non- normally distributed data, and proportion or counts for categorical data. All statistical tests were done using computer programs Microsoft Excel spreadsheet version 2007(Microsoft Corporation, New York, USA) and XLSTAT version 2015.4.01.20780 (Adinsoft) statistical program for Microsoft Windows. All tests were two tailed and $\mathrm{p}$ value less than 0.05 were considered statistically significant. Continuous data between groups were analyzed using Student's t test or Mann Whitney $U$ test depending on the normality of the data. Continuous data within a single group across various time points were analyzed using Friedman's Analysis of Variance followed by Wilcoxon's matched pair signed rank test post hoc analysis. Dichotomous data were analyzed using Pearson's chi square test or Fisher's exact test as applicable.

\section{Results}

After applying the inclusion and exclusion criteria, ninety patients, aged between 18-65 yrs, ASA grade I and II, scheduled to undergo intracranial tumor surgery, were studied.

The demographic characteristics were comparable in both groups [Table 1].

The time from induction of anesthesia to extubation was $275.82 \pm 24.25$ minutes and $275.56 \pm 22.63$ minutes in group $\mathrm{D}$ and group $\mathrm{C}$ respectively and it was comparable (p 0.957) [Figure 1].

Increase in heart rate was attenuated better in group $\mathrm{D}(\mathrm{P}<0.05)$ during specific time points which are known to cause considerable hemodynamic alterations, i.e after loading dose of dexmedetomidine ( $p$ 0.001), at the time of induction ( $\mathrm{p} 0.00$ ), laryngoscopy and intubation( $\mathrm{p}$ 0.001), head pin fixation(p 0.001), skin incision( $p$ 0.001), making of burr hole ( $p$ 0.001), opening of dura(p 0.001) and extubation(p 0.001) [Table 2].

Attenuation in systolic blood pressure, diastolic blood pressure, mean blood pressure were statistically significant throughout the intraoperative period (p 0.00) [Table 3, 4, 5]. 
The mean induction dose of propofol was $5.62 \pm 1.45 \mathrm{~mL}$ and $10.56 \pm 1.4 \mathrm{~mL}$ in group $\mathrm{D}$ and $\mathrm{C}$ respectively $(\mathrm{p}<0.0001)$. Total and hourly mean maintenance requirement of propofol in both groups were $41.38 \pm 9.16 \mathrm{~mL}$ and $8.28 \pm 1.83$ $\mathrm{mL}$ in group $\mathrm{D}$ and $132.89 \pm 20.43 \mathrm{~mL}$ and $28.12 \pm 3.72 \mathrm{~mL}$ in group $\mathrm{C}(\mathrm{p}<0.0001)$. Total and hourly requirement of fentanyl was significantly lower in group D $(\mathrm{p}<0.0001)$ [Table $6,7]$.

It was found that total seven (15\%) patients suffered from tachycardia in group D whereas it was 28 patients $(62 \%)$ in group $C(p<0.001)$. Use of Esmolol was significantly lower in group D (p $<0.0001$ ). Bradycardia occurred in 14 patients and 12 patients in group $\mathrm{D}$ and group $\mathrm{C}$ respectively ( $\mathrm{p}$ 0.897). Four (4 patients, 8.8\%) patients in group D received intravenous atropine to combat unstable bradycardia while it was three (3 patients, 7.14\%) (p 0.925) [Table8]. No significant difference in occurrence of both intraoperative hypertension and hypotension was found ( $\mathrm{p} 0.169$, p 0.94 respectively). Every cases of hypotension received medical intervention as per protocol. There was no difference in administration of phenylephrine ( $\mathrm{p}$ 0.7). Intravenous labetelol was used to treat hypertension only in 4 patients in group $\mathrm{D}$, whereas it was administered in 12 patients in group $C(p$ 0.015). No patient in group D whereas 5 patients suffered from hypertension at extubation ( $p$ 0.07). No significant difference in occurrence of postoperative nausea vomiting and shivering was present ( $\mathrm{p}$ 1.00, p 0.07 respectively).

Tracheal extubation was faster in group D (mean $16.58 \pm 4.9 \mathrm{~min}$ ) than group $\mathrm{C}$ (mean 33.6 \pm 7.5 min) $(\mathrm{p}<0.0001)$. Arterial $\mathrm{CO}_{2}$ tension was maintained in the range of $30-35 \mathrm{~mm} \mathrm{Hg}$ in both groups. After extubation every patient was fully conscious, well oriented and maintained $\mathrm{SpO}_{2}$ in the range of $95-100 \%$. Supplemental $\mathrm{O}_{2} 40 \%$ via face mask was provided to every patient postoperatively. Only two patients required analgesic in the immediate postoperative period in group $\mathrm{D}$, whereas 11 patients in group $\mathrm{C}$ required the same (p 0.026). Every patient was shifted to neuro ICU after extubation.

\section{Discussion}

We conducted the prospective randomized double blind placebo controlled study to examine whether addition of dexmedetomidine to a commonly administered balanced anesthetic regimen improves hemodynamics or not in patients undergoing elective craniotomy. The study demonstrated that, addition of continuous infusion of dexmedetomidine attenuated the hemodynamic responses at critical moments of anesthesia and surgery. As a secondary outcome measure, reduced intraoperative propofol and fentanyl requirement was noted.

Dexmedetomidine is a highly selective $\alpha-2$ adrenoreceptor agonist that has been shown to have sedative, analgesic and anesthetic sparing effects ${ }^{[4,6,7,8,9]}$. It causes dose dependant decrease in arterial blood pressure and heart rate associated with a decrease in serum nor-epinephrine concentration ${ }^{[10]}$. Among other major advantages, it's faster onset of action and shorter half life allow effective titration of drug dose.

The concept of neuroanesthesia includes several principals, the hemodynamic stability being most important. There are many causes responsible for hypertension during craniotomy. The final common pathway leading to perioperative hypertension appears to be activation of the sympathetic nervous system, as evidenced by increased plasma catecholamine concentration in patients after craniotomy [11]. A number of antihypertensive drugs are available to treat perioperative hypertension. Labetolol is commonly used to treat hypertension in this situation, but may not be used in certain group of patients because of its low potency, slow onset of peak effect and unpredictability in dose requirements ${ }^{[12]}$. Esmolol is effective to blunt tachycardia but mildly effective in treating perioperative hypertension and its use is further complicated by bradycardia ${ }^{[13]}$. Other drugs like nicardipine, hydralazine are cerebral vasodilator and may increase intracranial pressure and rarely 
used in treating hypertension in neurosurgical patients ${ }^{[14]}$. In some earlier reports, oral clonidine premedication provided attenuation of the hypertensive response to laryngoscopy and intubation and head holder application in patients undergoing supratentorial surgery [15] Dexmedetomidine decreased plasma epinephrine and nor-epinephrine level perioperatively ${ }^{[16]}$. Numerous studies in patients undergoing general and gynecological surgery have also shown that dexmedetomidine blunts the cardiovascular responses to intubation ${ }^{[6,8,9]}$. So, it was assumed that dexmedetomidine would attenuate hypertensive responses associated with stimulation during anesthesia and surgery. And our study corroborated this assumption. Two studies evaluated its role in patients undergoing intracranial surgery ${ }^{[2,3]}$. One study concluded that dexmedetomidine increased perioperative hemodynamic stability in patients undergoing brain tumor surgery and the trachea was extubated faster without respiratory depression ${ }^{[3]}$.

The gold standard of neuroanesthesia includes maintenance of anesthesia with isoflurane or propofol. Important advantage of propofol in general anesthesia is rapid emergence ${ }^{[17]}$. Propofol infusion is usually used for its remarkable safety features but various recent literatures have questioned regarding its prolonged infusion ${ }^{[18,19,20]}$. Although majority of such reports have involved its long-term administration in the ICU setting, recent evidence has also suggested the potential for intra operative complications even with short-term infusions $[18,19,20]$.

In view of the above observations the present study was designed to evaluate the effect of dexmedetomidine on hemodynamics and also requirement of propofol and fentanyl during intra operative period in elective intracranial tumor surgery. It demonstrated that, addition of continuous infusion of dexmedetomidine attenuated the hemodynamic responses at critical moments of anesthesia and surgery as well as during emergence from anesthesia. As a secondary outcome measure, it also reduced intraoperative propofol and fentanyl requirement. These findings were consistent with studies by Tanskanen P, et al and Scheinin B, et al. where they noted HR attenuation in intubation, but SBP

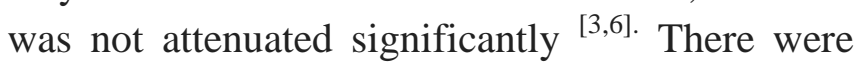
no significant differences between the groups in the HR at extubation. This was on the contrary of our findings. In our study, both HR and Blood Pressure were attenuated also at extubation (significant both statistically and clinically).

Increased risk of bradycardia and hypotension after rapid bolus administration in young healthy volunteers have been reported with dexmedetomidine in general and gynecological surgery ${ }^{[7,8]}$. In our study there was no difference in occurrence of bradycardia and hypotension in between groups. HR was better attenuated in dexmedetomidine group at different times which are known for their nociceptive stimulus. No significant difference in SBP, DBP and MAP were found after induction in both group. Significant attenuation of SBP, DBP and MAP occurred at intubation, head pin fixation, incision, making of burr hole, after opening of dura and during extubation (p 0.00) in dexmedetomidine group [Table 3,4,5].

There are some limitations of our study. We selected a constant dexmedetomidine infusion rate of $0.4 \mu \mathrm{g} / \mathrm{kg}$ after the initial loading dose of $1 \mu \mathrm{g} / \mathrm{kg}$. As we did not use target controlled infusion, so we selected a midrange dose with common methods of administration. As in normal clinical practice, it is possible that patients who differed in their ability to metabolize this drug received lower or higher effective doses. Factors possibly predictive of this did not differ between the groups. So with a study design in which the anesthesiologist would be permitted to titrate the dexmedetomidine dose, further improvements in hemodynamic stability with shorter awakening times might be demonstrated. 


\section{JMSCR Vol.||03||Issue ||08||Page 7236-7247||August}

Table-1: Demographic data

\begin{tabular}{|l|c|c|c|}
\hline Baseline demographic variables & Group D(n=45) & $\begin{array}{c}\text { Group } \\
\mathrm{C}(\mathrm{n}=45)\end{array}$ & p value \\
\hline Age (years) & $42.36 \pm 13.36$ & $38.33 \pm 13.13$ & 0.5 \\
\hline Sex (M/F) & $22 / 23$ & $19 / 26$ & 0.817 \\
\hline Body weight (kg) & $57.44 \pm 7.7$ & $57.02 \pm 7.8$ & 0.797 \\
\hline ASA grade 1 / grade 2 & $30 / 15$ & $28 / 17$ & 0.9 \\
\hline Type of brain tumour & 23 & 22 & 0.994 \\
Meningoma & 16 & 18 & \\
Glioma & 6 & 5 & 0.973 \\
Astrocytoma & $12 / 33$ & $13 / 32$ & 0.957 \\
\hline Presence of hypertension (yes/no) & & $275.56 \pm 22.63$ & \\
\hline Duration of surgery (minutes) & $275.82 \pm 24.25$ & & \\
\hline
\end{tabular}

Baseline demographics were comparable in both groups. No statistically significant differences seen between the groups.

Table 2: Comparison of Heart rate (beats per minute) at specific time points (mean \pm standard deviation)

\begin{tabular}{|l|c|c|c|}
\hline Specific time points & Group D $(\mathrm{n}=45)$ & Group C $(\mathrm{n}=45)$ & $\mathrm{p}$ value \\
\hline T0 & $77.31 \pm 11.75$ & $79.84 \pm 14.22$ & 0.357 \\
\hline T1 & $69.91 \pm 11.11$ & $79.11 \pm 14.22$ & $* 0.001$ \\
\hline T2 & $66.96 \pm 11.7$ & $78.37 \pm 18$ & $* 0.00$ \\
\hline T3 & $75.22 \pm 15.7$ & $93.97 \pm 19$ & $* 0.0001$ \\
\hline T4 & $73.38 \pm 14.58$ & $86.97 \pm 12.23$ & $* 0.0001$ \\
\hline T5 & $72.18 \pm 13.66$ & $85.15 \pm 14.89$ & $* 0.0001$ \\
\hline T6 & $71.69 \pm 13.57$ & $83.91 \pm 13.59$ & $* 0.0001$ \\
\hline T7 & $70.8 \pm 12.64$ & $82.6 \pm 13.73$ & $* 0.0001$ \\
\hline T8 & $76.1 \pm 12$ & $96.22 \pm 15.7$ & $* 0.0001$ \\
\hline
\end{tabular}

Table 2 shows intraoperative attenuation of heart rate at specific time points mean \pm standard deviation. There were statistically significant differences seen between the groups. * denotes statistically significant differences between the groups. Data were collected at following specific time points: T0 - baseline, T1- after loading dose of drug, T2 - after induction, T3 - intubation, T4 - head pin fixation, T5 - incision, T6 - burr hole, T7 - at opening of dura, T8- after extubation 
Table 3. Comparison of Systolic blood pressure $(\mathrm{mm} \mathrm{Hg})$ attenuation between Group D and Group C.

\begin{tabular}{|l|l|l|l|}
\hline Specific time points & Group D $(\mathrm{n}=45)$ & Group C $(\mathrm{n}=45)$ & $\mathrm{p}$ value \\
\hline T0 & $127.56 \pm 15.48$ & $126.4 \pm 15.78$ & 0.721 \\
\hline T1 & $124.29 \pm 16.72$ & $127.66 \pm 15.25$ & 0.317 \\
\hline T2 & $113.53 \pm 14.16$ & $108.22 \pm 12.25$ & 0.057 \\
\hline T3 & $115.27 \pm 12.14$ & $137.42 \pm 16.7$ & $*<0.0001$ \\
\hline T4 & $116.33 \pm 12.86$ & $126.84 \pm 15$ & $* 0.000$ \\
\hline T5 & $112.36 \pm 10.75$ & $122.95 \pm 15.7$ & $* 0.000$ \\
\hline T6 & $111.6 \pm 13.93$ & $121.82 \pm 15$ & $* 0.001$ \\
\hline T7 & $112.78 \pm 13.1$ & $125.55 \pm 13.71$ & $*<0.0001$ \\
\hline T8 & $130.91 \pm 14.58$ & $149.62 \pm 12.8$ & $*<0.0001$ \\
\hline
\end{tabular}

Table 3 shows Intraoperative systolic blood pressure measurements at specific time points mean \pm standard deviation. There were statistically significant differences seen between the groups. Data were collected at following specific time points: T0 - baseline, T1- after loading dose of drug, T2 - after induction, T3 - intubation, T4 head pin fixation, T5 - incision, T6 - burr hole, T7 - at opening of dura, T8- after extubation. * denotes statistically significant differences between the groups.

Table 4. Comparison of diastolic blood pressure $(\mathrm{mm} \mathrm{Hg})$ attenuation between Group D and Group C.

\begin{tabular}{|l|l|l|l|}
\hline Specific time points & Group D $(\mathrm{n}=45)$ & Group C $(\mathrm{n}=45)$ & $\mathrm{p}$ value \\
\hline T0 & $77.44 \pm 10.3$ & $77.93 \pm 10.5$ & 0.824 \\
\hline T1 & $72.1 \pm 11.11$ & $77.82 \pm 10.3$ & $* 0.011$ \\
\hline T2 & $67.87 \pm 10.15$ & $65.64 \pm 8.6$ & 0.263 \\
\hline T3 & $69 \pm 10.09$ & $84.13 \pm 11.5$ & $*<0.0001$ \\
\hline T4 & $71.84 \pm 9.72$ & $78.89 \pm 9.5$ & $* 0.000$ \\
\hline T5 & $71 \pm 8.7$ & $80 \pm 10.3$ & $*<0.0001$ \\
\hline T6 & $70.76 \pm 9.93$ & $80.16 \pm 13.6$ & $* 0.000$ \\
\hline T7 & $70.89 \pm 11.07$ & $83.84 \pm 10.4$ & $*<0.0001$ \\
\hline T8 & $84.4 \pm 8.48$ & $96.62 \pm 5.5$ & $*<0.0001$ \\
& & & \\
\hline
\end{tabular}

Table 4 shows Intraoperative diastolic blood pressure measurements at specific time points mean \pm standard deviation. There were statistically significant differences seen between the groups. Data were collected at following specific time points: T0 - baseline, T1- after loading dose of drug, T2 - after induction, T3 - intubation, T4 head pin fixation, T5 - incision, T6 - burr hole, $\mathrm{T} 7$ - at opening of dura, T8- after extubation. denotes statistically significant differences between the groups. 
Table 5. Comparison of mean arterial pressure ( $\mathrm{mm} \mathrm{Hg}$ ) in between Group D and Group C.

\begin{tabular}{|l|c|c|c|}
\hline Specific time points & Group D (n=45) & $\begin{array}{c}\text { Group C } \\
(\mathrm{n}=45)\end{array}$ & p value \\
\hline T0 & $94.16 \pm 10.65$ & $94.16 \pm 11.2$ & 1.000 \\
\hline T1 & $90.44 \pm 14.37$ & $95 \pm 10$ & 0.093 \\
\hline T2 & $83.00 \pm 10.3$ & $79.91 \pm 8.8$ & 0.084 \\
\hline T3 & $84.44 \pm 9.55$ & $101.91 \pm 12.2$ & $*<0.0001$ \\
\hline T4 & $86.64 \pm 9.98$ & $95 \pm 10.2$ & $* 0.001$ \\
\hline T5 & $84.84 \pm 8.72$ & $94.38 \pm 11.4$ & $*<0.0001$ \\
\hline T6 & $84.4 \pm 10.54$ & $94 \pm 13.4$ & $* 0.000$ \\
\hline T7 & $84.78 \pm 11.25$ & $97.69 \pm 10.9$ & $*<0.0001$ \\
\hline T8 & $99.89 \pm 9.61$ & $114.29 \pm 6.9$ & $*<0.0001$ \\
\hline
\end{tabular}

Table 5 shows groups.Intraoperative systolic blood pressure measurements at specific time points mean \pm standard deviation. There were statistically significant differences seen between the groups. Data were collected at following specific time points: T0 - baseline, T1- after loading dose of drug, T2 - after induction, T3 intubation, T4 - head pin fixation, T5 - incision, T6 - burr hole, T7 - at opening of dura, T8- after extubation. * denotes statistically significant differences between the

Table 6. Comparison of Propofol requirement $(\mathrm{mL})$ in both groups.

\begin{tabular}{|l|c|c|c|}
\hline Requirement of Propofol & Group D $(\mathrm{n}=45)$ & Group C $(\mathrm{n}=45)$ & $\mathrm{p}$ value \\
\hline Induction $(\mathrm{mL})$ & $5.62 \pm 1.45$ & $10.56 \pm 1.4$ & $*<0.0001$ \\
\hline Hourly maintenance $(\mathrm{mL})$ & $8.28 \pm 1.83$ & $28.12 \pm 3.72$ & $*<0.0001$ \\
\hline Total maintenance dose $(\mathrm{mL})$ & $41.38 \pm 9.16$ & $28.12 \pm 3.72$ & $*<0.0001$ \\
\hline
\end{tabular}

Propofol requirement as induction and maintenance agent (both hourly and total requirement) presented and compared here as mean \pm standard deviation in between group $\mathrm{D}$ and group C. Statistically significant differences are present as denoted by $*$ in Table no. 6 .

Table 7. Comparison of Fentanyl requirement $(\mu \mathrm{g})$ in both groups.

\begin{tabular}{|l|l|l|l|}
\hline Requirement of Fentanyl $(\mu \mathrm{g})$ & Group D $(\mathrm{n}=45)$ & Group C $(\mathrm{n}=45)$ & $\mathrm{p}$ value \\
\hline Hourly requirement & $52.76 \pm 10.27$ & $93.78 \pm 12.5$ & $*<0.0001$ \\
\hline Total requirement & $244.33 \pm 43.54$ & $448.33 \pm 74.89$ & $*<0.0001$ \\
\hline
\end{tabular}

Table 7 shows Fentanyl requirement as induction and maintenance agent (both hourly and total requirement) and data is compared here as mean \pm standard deviation in between group D and group C. Statistically significant differences are present as denoted by *. 
Table 8. Adverse events and interventions done in Group D and Group C.

\begin{tabular}{|l|c|c|c|}
\hline Adverse Events and interventions & $\begin{array}{c}\text { Group D } \\
(\mathrm{n}=45)\end{array}$ & $\begin{array}{c}\text { Group C } \\
(\mathrm{n}=45)\end{array}$ & p value \\
\hline Tachycardia(yes/no) & $7 / 38$ & $28 / 17$ & $*<0.001$ \\
\hline Bradycardia (yes/no) & $14 / 31$ & $12 / 35$ & 0.897 \\
\hline Hypotension(yes/no) & $5 / 40$ & $4 / 41$ & 0.940 \\
\hline Intraoperative hypertension (yes/no) & $5 / 40$ & $12 / 33$ & 0.169 \\
\hline Hypertension at extubation (yes/no) & $0 / 45$ & $5 / 40$ & 0.071 \\
\hline Use of Labetelol (yes/no) & $2 / 43$ & $12 / 33$ & $* 0.015$ \\
\hline $\begin{array}{l}\text { Use of Phenylephrine } \\
\text { (yes/no) }\end{array}$ & $2 / 43$ & $4 / 41$ & 0.700 \\
\hline Use of Esmolol (yes/no) & $5 / 40$ & $26 / 19$ & $*<0.0001$ \\
\hline Use of Atropine (yes/no) & $4 / 41$ & $3 / 42$ & 0.925 \\
\hline Intravenous Paracetamol postoperatively (yes/no) & $2 / 43$ & $11 / 34$ & $* 0.026$ \\
\hline Post operative nausea and vomiting (yes/no) & $0 / 45$ & $0 / 45$ & 1.000 \\
\hline Shivering (yes/no) & $2 / 43$ & $9 / 36$ & 0.07 \\
\hline
\end{tabular}

Table 8 shows adverse intraoperative events and their management in both the groups. Lesser number of patients in Group D suffered from tachycardia than found in Group C $(\mathrm{p}<0.001)$. Also intravenous Labetelol use for intraoperative hypertension, intravenous Esmolol administration for tachycardia and postoperative analgesic requirement was found to be lesser in Group D and it was statistically significant $(\mathrm{p}<0.05)$.

Incidence of bradycardia, hypotension, intraoperative hypertension, hypertension at extubation, administration of Phenylephrine and Atropine, postoperative nausea and vomiting, and shivering found as having no significant difference between both groups ( $p>0.05)$. *denotes statistically significant $\mathrm{p}$ value.
Figure 1. Comparison of extubation time

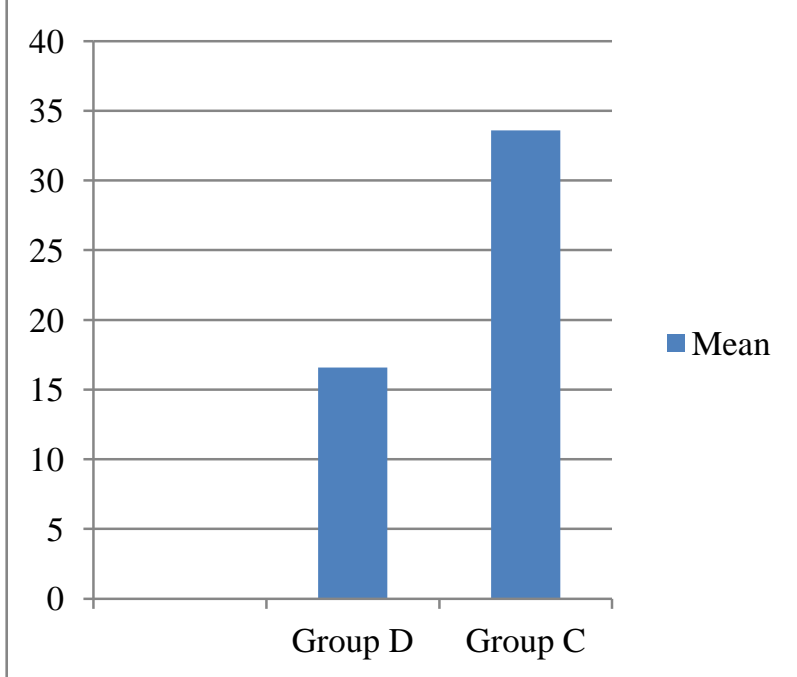

Figure1. Comparison of extubation time in group $\mathrm{D}$ and group $\mathrm{C}$.

Mean time for extubation was $16.58 \pm 4.9$ minutes in group $\mathrm{D}$, and $33.6 \pm 7.5$ minutes in group $\mathrm{C}$. There was statistically significant difference $(P<$ 0.0001). 


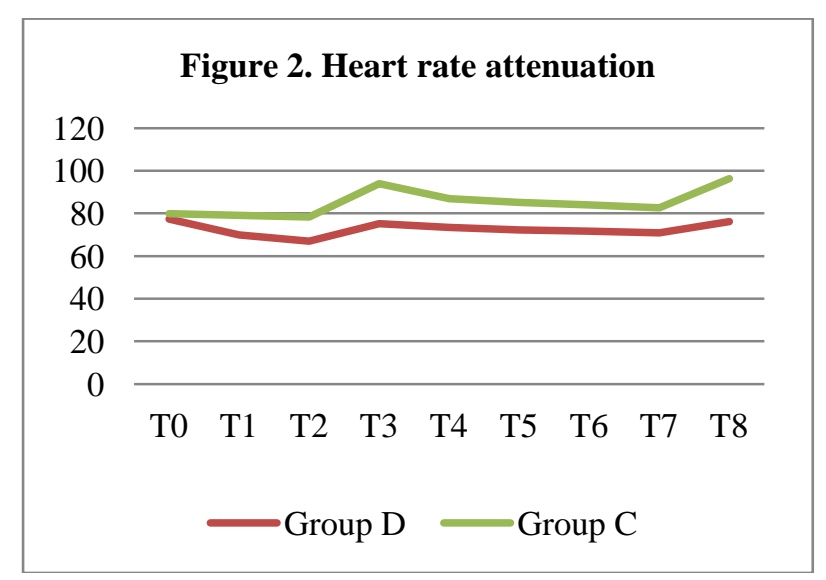

Figure 2. Comparison of Heart rate (beats per min) attenuation in both groups.

Figure 2 shows that mean heart rate attenuation was better in Group D.

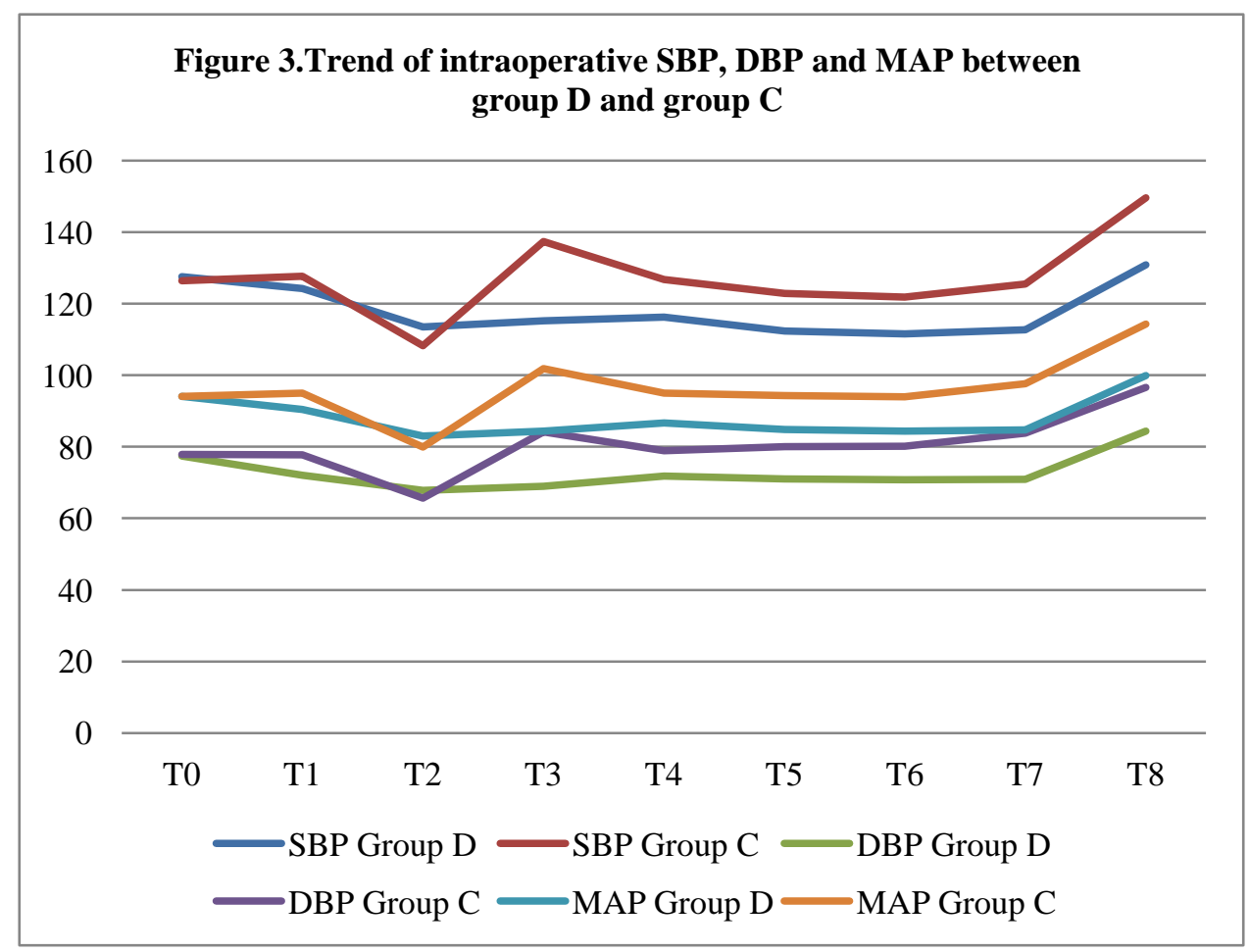

Figure 3. Comparison of trend during intraoperative systolic, diastolic and mean blood pressure between both groups.

Figure 3 compares the trend of Systolic, Diastolic and Mean blood pressure of Group D and Group
C. Descriptive data of Group D was found to have better attenuation in the above figure. 


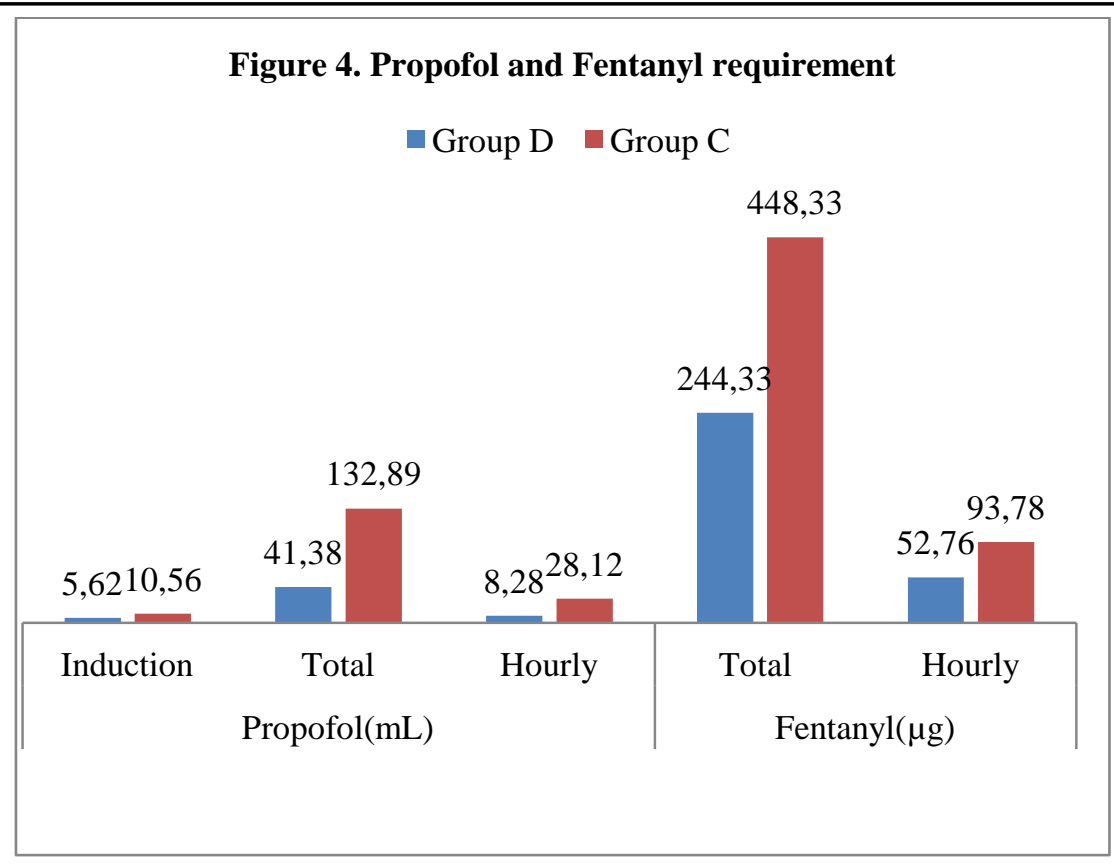

Figure 4. Comparison of Propofol and Fentanyl requirement between Group D and Group C.

Figure 4 showing and comparing the requirement of Propofol and Fentanyl between the groups. Data are presented here as mean.

\section{Conclusion}

In conclusion, a continuous infusion of dexmedetomidine maintained hemodynamic stability better than placebo in patients undergoing intracranial surgery without increasing the incidence of hypotensive episodes or bradycardia. It also reduced the intraoperative propofol and fentanyl requirement. In addition, patients treated with dexmedetomidine were extubated earlier and required less analgesic in the immediate postoperative period than the control group.

\section{Acknowledgement: Nil.}

\section{References}

1. Basali A, Mascha EJ, Kalfas I, Schubert A. Relation between perioperative hypertension and intracranial hemorrhage after craniotomy. Anesthesiology 2000; 93:4854.

2. Gunes Y, Gunduz M, Ozcengiz D, Ozbek $\mathrm{H}$, Isik G.Dexmedetomidine-remifentanil or propofol-remifentanil anesthesia in patients undergoing intracranial surgery. Neurosurg Q 2005; 15: 122-6.

3. Tanskanen P, Kytta J, Randell T, Aantaa R. Dexmedetomidine as an anaesthetic adjuvant in patients undergoing intracranial tumor surgery: a double-blind, randomized and placebo-controlled study. Br J Anaesth 2006;97: 658-65.

4. Hall JE, Uhrich TD, Barney JA, Shahbaz RA, Ebert TJ. Sedative, amnestic, and analgesic properties of small dose dexmedetomidine infusions. Anesth Analg 2000; 90: 699-705.

5. Bekker A, Sturaitis M. Dexmedetomidine for neurological surgery. Neurosurgery 2005; 57: 1-10.

6. Scheinin B, Lindgren L, Randell $\mathrm{T}$, Scheinin H, Scheinin M. Dexmedetomidine attenuates sympathoad-renal response to tracheal intubation and reduces the need for thiopentone and peroperative fentanyl. Br J Anaesth 1992; 68: 126-31.

7. Belleville JP, Ward DS, Bloor BC, Maze M. Effects of intravenous dexmedetomidine in humans. I. Sedation, ventilation, and metabolic rate. Anesthesiology 1992; 77: 1125-33. 
8. Aho M, Erkola O, Kallio A, Scheinin H, Korttila K. Dexmedetomidine infusion for maintenance of anesthesia in patients undergoing abdominal hysterectomy. Anesth Analg 1992; 75: 940-6.

9. Aantaa R, Jaakola ML, Kallio A, Kanto J. Reduction of the minimum alveolar concentration of isoflurane by dexmedetomidine. Anesthesiology 1997; 86: 1055-60.

10. Kallio A, Scheinin M, Koulu M, et al. Effects of dexmedetomidine, a selective alpha 2- adrenoceptor agonist, on hemodynamic control mechanisms. Clin Pharmacol Ther 1989; 46: 33-42.

11. Olsen K, Pedersen C, Madsen J, Ravn L, Schifter S. Vasoactive modulators during and after craniotomy: relation to postoperative hypertension. J Neurosurg Anesth 2002; 14: 171-9.

12. Kross R, Ferri E, Leung D, Pratila M, Broad C, Veronesi M, Melendez J. A comparative study between a calcium channel blocker (nicardipine) and combined $\alpha$ - $\beta$-blocker (labetelol) for the control of emergence hypertension during craniotomy for tumor surgery. Anesth Analg 2000; 91: 904-9.

13. Haas C, LeBlac J. Acute postoperative hypertension: a review of therapeutic options. Am J Health- Syst Pharm 2004; 61: 1661-73.

14. Akopov S, Simonian N, Kazarian A. Effects of nifedipine and Nicardipine on regional cerebral blood flow distribution in patients with arterial hypertension. Methods Find Exp Clin Pharmac 1996; 18: 685-92.

15. Chadha R, Padmanabhan V, Joseph A, Mohandas K. Oral clonidine pretreatment for hemodynamic stability during craniotomy. Anaesth Intensive Care 1992; 20: 341-4.

16. Bekker A, Basile J, Gold M, Riles T, Adelman M, Cuff G, Mathew J, Goldberg
J. Dexmedetomidine for awake carotid carotid Endarterectomy: efficacy, hemodynamic profile, and side effects. J Neurosurg Anesth 2004; 16: 126-35.

17. Marshall CA, Jones RM, Bajorek PK, Cashman JN. Recovery characteristics using isoflurane or propofol for maintenance of anaesthesia: a double-blind controlled trial. Anaesthesia 1992; 47; 461-6.

18. Burow, BK. Johnson ME. Packer DL. Metabolic Acidosis Associated with Propofol in the Absence of Other Causative Factors. Case report. Anesthesiology 2004; 101:239-41.

19. Salengros JC, Velghe-Lenelle CE, Bollens R, Engelman E, Barvais L. Lactic Acidosis during Propofol-Remifentanil Anaesthesia in an Adult. Case report. Anesthesiology 2004; 101:241-3.

20. Hatch DJ. Propofol infusion syndrome in children. Lancet 1999; 353: 1117-18. 